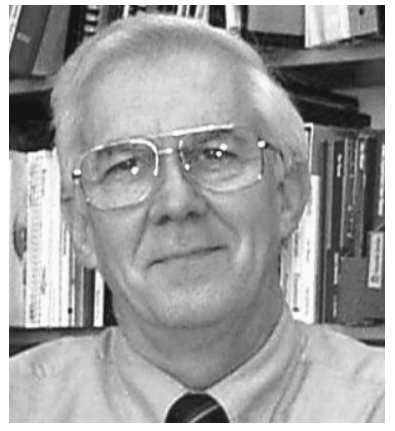

\section{The 1.5-Liter Merit Function}

In the day-to-day work of design and development, an engineer's attention is given over to quantifiable effects that can establish performance and potential for practical use. We tend to deal with first making a device or technique work, then refining it to make it work well...and cheaply. Much of this effort depends on observation, testing, evaluation, and decision.

For most engineers, these processes are applied to a narrow range of devices, over a long time. These same processes can be used on other fields to derive as much pleasure and intellectual stimulation as in engineering. For the field I have in mind, the variety is larger, distinctions are not as definite, but the challenge to quantify and describe can be just as satisfying. The field I refer to is...wine.

I am not what you would call a wine snob. I will sip plonk at any reception, provided there is something to nibble. But what I really enjoy doing is poking around in a wine shop or the wine section of a supermarket, looking for an interesting wine.

Because both my wife and I came from working class families in Ohio, our early contacts with wines were limited. Mine was communion wine as an altar boy; my wife's wine was of the homemade variety made on the farm where she grew up as a daughter of Polish immigrants. On the whole, these wines tended to be rather sweet and as teens and young adults neither of us considered this adult drink to be of any consequence. Neither my Irish family and nor her family considered wine to be a big deal. That is, no one treated it as a forbidden drink in front of their kids. We continued that approach with our children. Now grown up, only one of our four children has wine with us at our customary Sunday dinners.

So how did we develop a taste for wines? In my case, I was in my first year of graduate school at Ohio State, living in a boarding house on 15th Street in Columbus. Two of the other boarders and I decided we wanted to learn something about wines, so we read a bit and shared one bottle of wine each week. This being long before the age of the Internet, the amount of information was modest. The concept of a wine tasting was way beyond us both in concept and in budget. But over the months, we gained some idea of what we liked and what we didn't. This was also the era when the names of wines tended to be the names of the vineyard owners: Gallo, Paul Masson, and Taylor. Labels like Turning Leaf, Ravenswood, and Dry Creek were far in the future.

While I was a graduate student at Johns Hopkins, we scrimped by on a graduate student salary, augmented by a nurse's pay. Our wine was purchased in gallon jugs, but not kept there. We bought a corker and used our baby bottle sterilizer to prepare beer bottles to hold the wine. It was only much later that we abandoned this economic measure.

I know a number of persons in science and engineering that also have a strong interest in wines. I have never asked them what attracted them to wines, but some of the attractions that I find in wines are their variety, their cost, and their "unquantitativeness." By the latter term I mean that with exception of its alcohol, tannin, and sugar content, the description of a wine is qualitative and must be put into words. In many cases, the wines are compared to various fruits, flowers, and other flora. The result is that, in comparison to the more straightforward declarations of our day jobs, discussions on the varieties of wines, their taste, geography, and vintage are wide-ranging and transferable to the non-technical world outside our jobs. With the exception of dining, wine is one of the few places that provides opportunities for shared experiences. You can go to the local multiplex and see Hollywood's latest collection of special effects and talk about the movie later, but that doesn't compare to a group of people sharing a bottle of wine.

Another aspect of wine and engineers that comes in for a good deal of discussion is cost. Compared to the price tags for cars, boats, and real estate, the cost of wine is relatively modest. The story of the bargain buy holds the same status as the big fish story does for those who prefer to get up early and slog through cold water. The question is usually posed as "Where can you explore for some good wines at a modest cost?" The answer, to put it in daytime terms: it's a problem of optimization. The exact merit function, I suppose, depends on your pocketbook and experience. 
Over the years we have tended to buy a few bottles of wine for special dinners, but for everyday use, we get a 1.5-liter bottle and use it over a number of days. Although this size and type of wine is the latter day equivalent of jug wine, the quality is so much better now. I sometimes imagine that when I retire I will set up a web page that discusses and rates 1.5-liter wines. It would be sort of a downscale version of the Wine Advocate. With the excellent quality of the wines, including the Australian vari- etals, anyone paying a little attention can drink some very nice wines for not a lot of money. I will never end up with a cellar and a bunch of rare wines to pass on to my children, but I will have had a great deal of fun and satisfaction working on my merit function.

Donald C. O'Shea Editor 